\title{
Optimal Cutoff of the TG/HDL-c ratio for Cardiovascular Risk in Hypertensive and Diabetic Patients Monitored by Primary Health Care in a city in Minas Gerais
}

Eunice Ferreira da Silva, ${ }^{\circledR}$ Rosângela Minardi Mitre Cotta, ${ }^{1}{ }^{\circledR}$ Érica Toledo Mendonça, ${ }^{\circledR}$ Deíse Moura de Oliveira, ${ }^{\circledR}$ Silvia Almeida Cardoso, ${ }^{\oplus}$ Renata Maria Colodette, ${ }^{2 \oplus}$ Tiago Ricardo Moreira ${ }^{\circledR}$

Universidade Federal de Viçosa, ${ }^{1}$ Viçosa, MG - Brazil

Fundação Oswaldo Cruz, ${ }^{2}$ Rio de Janeiro, RJ - Brazil

\section{Abstract}

Background: The analysis of the atherogenic potential of the lipid profile for biomarkers, such as the TG/HDL-c ratio, predicts cardiovascular risk better than isolated lipids.

Objective: To identify the TG/HDL-c cutoff points for multiple risks (hypertension, Diabetes Mellitus, obesity) and to evaluate the association between sociodemographic, clinical, laboratory, anthropometric, and life habit variables and the TG/HDL-c ratio in hypertensive and/or diabetic individuals in the context of Primary Health Care.

Methods: This was a cross-sectional study with 833 hypertensive and/or diabetic patients, conducted between August 2017 and April 2018. The cutoff point of the TG/HDL-c were obtained by the ROC curve. Cardiovascular risk was discriminated by TG/HDL-c, categorized by the cutoff and evaluated in relation to multiple risks. The magnitude of the association between TG/HDL-c and independent variables was estimated by logistic regression. The significance level of $\mathrm{p}<0.05$ was adopted for all tests.

Results: The cutoff values of TG/HDL-c (3.26 for men and 2.72 for women) were more sensitive and less specific than those in the literature. Women (OR=1.90 and 95\% CI 1.13-3.20) and men (OR=4.58 and 95\% CI 1.78-11.76) with multiple risks, and white men, alcohol users, with a history of stroke, had a higher chance of altered GT/HDL-c. Increases in glycosylated hemoglobin, glycemia, and phosphorus in women, and cholesterol, glycemia, and microalbuminuria in men increased the chances of altered TG/HDL-c. Being a former smoker and black reduced the chance of altered TG/HDL-c in women.

Conclusions: TG/HDL-c proved to be a good indicator for habitual use in Primary Care.

Keywords: Hypertension, Diabetes Mellitus, Primary Health Care, Dyslipidemias, Biomarkers.

\section{Introduction}

Currently, cardiovascular diseases (CVD) are one of the most important public health problems in the world and one of the main causes of prolonged hospitalization and health expenditures in Brazil., ${ }^{1,2}$ Among CVD, coronary artery disease (CAD) stands out as the leading cause of death in Brazil $l^{3,4}$ and worldwide. ${ }^{3}$

Dyslipidemias are related to the development of atherosclerosis and, consequently, CAD. ${ }^{5}$ Early detection of individual cardiovascular risk (CVR) is important to prevent $\mathrm{CVD}^{1,5,6}$ define therapy ${ }^{6}$ and reduce complications ${ }^{1}$ and mortality. ${ }^{5}$ CVD prevention is a public health priority, especially in high-risk individuals, such as those diagnosed with arterial hypertension (AH) or Diabetes Mellitus (DM). The use of CVR predictors is important in clinical practice, ${ }^{2,7,8}$ and the analysis of the atherogenic potential of lipid profile by biomarkers predicts CAD better than the isolated analysis of lipids, as it reflects the interactions between atherogenic and protective lipid fractions. ${ }^{9}$

Mailing Address: Eunice Silva

Av. Peter Henry Rolfs, s/n. Postal Code: 36570-000, Campus Universitário, Viçosa, MG - Brazil

E-mail: eunice.f.silva@ufv.br 
CVR indices included the Castelli I Indices (CT/HDL-c ratio) and II (LDL-c/HDL-c ratio), ${ }^{1}$ and the Framingham score. ${ }^{1,6}$ Among the estimates calculated from routine laboratory parameters, covered by Primary Health Care (PHC), the proportion of triglycerides in relation to HDL cholesterol (TG/HDL-c ratio) is easily obtained from the patient's lipid profile. ${ }^{5,7-9}$ The TG/HDL-c ratio, proposed by Gaziano et al. ${ }^{10}$ as a strong lipid predictor for acute myocardial infarction, has been used as an indicator of dyslipidemias ${ }^{8}$ and cardiometabolic risks (obesity, AH and DM), ${ }^{5,7-9}$ being a potent predictor of the development of CAD. $8,9,11$

The TG/HDL-c ratio dispenses with personnel and specialized techniques, ${ }^{12}$ it is a safe, economical, fast-to-obtain, practical, and easy-to-use atherogenic marker. ${ }^{2,7}$ For these reasons, its use can be especially considered in $\mathrm{PHC}^{8}$

Several studies have suggested cutoff points to indicate CVR, whether equal values for Brazilian elderly men and women ${ }^{8}$ or different values for Japanese adult men and women. ${ }^{5}$ However, studies whose cutoffs have been calculated specifically for the Brazilian hypertensive and/or diabetic population are unknown. Thus, the present study's objective is to identify the cutoff of the TG/HDL-c ratio for multiple risks ( $\mathrm{AH}, \mathrm{DM}$ and obesity) and to evaluate sociodemographic, clinical, laboratory, anthropometric, and life habit factors associated with the altered TG/HDL-c ratio in individuals diagnosed with $\mathrm{AH}$ and/or DM, in the context of PHC.

\section{Methods}

\section{Study design, sample size calculation, and participants}

This is a cross-sectional study that is part of a larger project, ${ }^{13}$ which followed the ethical precepts of Resolution 466/2012 of the National Health Council and was approved by the Ethics Committee of the Federal University of Viçosa (CAAE: 47356115.3.0000.5153). This study's participants included adult and elderly users of the Brazilian Unified Health System (SUS in Portuguese), in a municipality of Minas Gerais, Brazil. The minimum sample (719) was calculated (Statcalc, Epi-Info ${ }^{\circledR}$ ) based on the population of 6,624 hypertensive and/or diabetic patients registered according to the Municipal Health Department. The final sample included 833 individuals over
18 years of age, who were hypertensive and/or diabetic and who received followed up by the Family Health Strategy. Excluded from the data collection were those individuals who did not continue their follow-up visits, as well as pregnant women, abusive users of alcohol and/or drugs, individuals with severe clinical conditions, and those with established chronic kidney disease (CKD).

\section{Data collection}

Data were collected in the Basic Health Units between August 2017 and April 2018. Sociodemographic data, life habits, and health care were collected through semi-structured questionnaires, previously tested in a pilot study, applied by trained researchers. Blood pressure was measured by trained professionals and classified according to the $7^{\text {th }}$ Brazilian Guidelines on Arterial Hypertension (2016). ${ }^{14}$

The weight, in kilograms $(\mathrm{Kg})$, was obtained on an electronic scale with a capacity of $150 \mathrm{~kg}$ and division of 50 grams. Stature, in meters, was measured in a portable anthropometer, with a metal platform for positioning of individuals and dismountable wooden column, with millimeter tape and cursor for reading, according to Jelliffe techniques (1966). ${ }^{15}$ The body mass index (BMI), calculated by the Weight/Stature ${ }^{2}$ ratio $\left(\mathrm{Kg} / \mathrm{m}^{2}\right)$, was classified according to World Health Organization (WHO) criteria $(2000)^{16}$ for adults, and Lipschitz criteria (1994) ${ }^{17}$ for the elderly. The waist and hip perimeters were measured in centimeters $(\mathrm{cm})$ with inextensible measuring tape. The hip perimeter values were obtained at the level of the maximum extension of the buttocks, with the tape positioned transversely to the measured segment, on the skin, without excessive pressure. Waist perimeter values were obtained at the midpoint between the iliac crest and the external face of the last rib and classified as "increased" in relation to the risk for non-communicable chronic diseases when they presented measurements of $\geq 94 \mathrm{~cm}$ for men and of $\geq 80 \mathrm{~cm}$ for women, according to the WHO (2000). ${ }^{16}$ The waist-hip (WHR) and waist-height (WHT) relationships were calculated by dividing the waist perimeter values by hip perimeter and stature, respectively. The reference values for CVR of the WHR for men $(\geq 0.90)$ and women $(\geq 0.85)$ were those recommended by the WHO (2000), ${ }^{16}$ while the WHT $(\geq 0.5)$ between genders was recommended by Ashwell and Hsieh (2005). ${ }^{18}$ 
Biological samples were collected after 12 hours of fasting, and the biological materials were analyzed in an accredited laboratory, using commercial kits and techniques, together with reference criteria. Microalbuminuria (mg/dL) tests were performed, as were tests for serum albumin, phosphorus, calcium, and creatinine $(\mathrm{mg} / \mathrm{dL})$; fasting glucose $(\mathrm{FG})(\mathrm{mg} / \mathrm{dL})$; glycosylated hemoglobin (HbA1c) (\%); triglycerides (TG) $(\mathrm{mg} / \mathrm{dL})$; total cholesterol (TC) and fractions high lipoproteins (HDL-c) and low densities (LDL-c) (mg/dL). The TG/HDL-c ratio (dependent variable) was calculated from plasma lipid dosages, dividing the TG values by cholesterol linked to HDL-c. The results of FG and $\mathrm{HbA} 1 \mathrm{c}$ were classified as altered (FG-126mg/dL and HbA1c-6.5\%) according to the criteria of the American Diabetes Association, adopted by the Brazilian Diabetes Society (2018). ${ }^{19}$

The Glomerular Filtration Rate (GFR) (mL/min/1.73 $\mathrm{m}^{2}$ ) was estimated from serum creatinine by the Chronic Kidney Disease Epidemiology Collaboration (CKD-EPI) equation. The criterion for CKD was based on Kidney Disease: Improving global Outcomes (KDIGO 2012), ${ }^{20}$ considering the values of GFR $<60 \mathrm{~mL} / \mathrm{min} / 1.73 \mathrm{~m}^{2}$.

\section{Statistical analysis}

Statistical analyses were performed using computer software programs (SPSS version 20). For descriptive analysis and characterization of the population, absolute and relative frequencies of categorical and mean variables, medians, standard deviations, and interquartile intervals of continuous variables were estimated. Pearson's chi-square test was used to verify associations between categorical variables. The statistically important differences between the continuous variables were verified by the unpaired Student t-tests (parametric) or Mann Whitney U (non-parametric) test, according to the normality of the data. The normality of the distribution was tested by the Shapiro-Wilk test. The significance level of $p<0.05$ was adopted for all tests.

The cutoff of the TG/HDL-c ratio for CVR discrimination in relation to multiple risk factors $(\mathrm{AH}$, $\mathrm{DM}$, and obesity classified by BMI) were obtained by the Receiver Operating Characteristic (ROC) curve. The ideal cutoff points were selected maximizing the Youden index. The discrimination of the TG/HDL-c ratio was measured by the area under the ROC curve (AUC). The $95 \%$ confidence interval (CI) for AUC was estimated by the DeLong method (1988). The sensitivity, specificity, and accuracy of the identified cutoff points, and others already described in the literature, ${ }^{5,8}$ were presented.

The magnitude of the association between the TG/HDL-c ratio (categorized by the obtained cutoff points) and the population characteristics were estimated by logistic regression models. The analyses were stratified by sex. Bilateral probability (p) values of less than 0.05 were considered to indicate statistical significance in the multivariate model. To evaluate the magnitude of the associations, the Odds Ratio (OR) and respective $95 \%$ CI were used.

\section{Results}

Table 1 shows the characteristics of the subjects by gender. The participants were classified as overweight by BMI and presented WHR and WHT in the increased CVR range. The median values of BMI and WHT in women and WHR in men were higher. CVR-related variables were significantly higher in women, and 27 men and 87 women accumulated the three risk factors.

Figure 1 shows the results of the ROC analysis for the relationships between TG/HDL-c and RCV factors. The optimal cutoff values of the TG/HDL-c ratio for multiple risks were 3.26 for men and 2.72 for women $(\mathrm{p}<0.001)$, lower than the reference ratio $(=3.5)$ for both genders, ${ }^{8}$ as well as for women $(=3.75)^{5}$ and for men (=3.0). ${ }^{5}$ The new values showed greater accuracy and sensitivity, and lower specificity than conventional ones (Table 2).

Considering the cutoff points established by the ROC curve, the TG/HDL-c ratio was categorized as adequate ( $<3.26$ for men, $<2.72$ for women) and changed ( $\geq 3.26$ for men, $\geq 2.72$ for women). Men with altered TG/HDL-c ratio were observed as more obese; more frequently of multiple risks; higher median values of weight, BMI, hip perimeter, WHT, and WHR; higher waist perimeter averages; higher mean levels of TG, FG, HbA1c, creatinine, and albumin; and lower HDL-c. A higher proportion of men with adequate TG/HDL-c used hypoglycemic agents (Table 3). Women with an altered TG/HDL-c ratio were observed as more obese, with a higher frequency of multiple risks; median values of weight, BMI, hip perimeter, WHT, and WHR; higher waist perimeter averages; higher median levels of TG and FG; and lower HDL-c when compared to those with an adequate TG/HDL-c ratio. A higher proportion of women 
Table 1 - Characteristics of hypertensive and/or diabetic patients followed by the Family Health Strategy in Viçosa, Minas Gerais, Brazil, 2017-2018

\begin{tabular}{|c|c|c|c|c|}
\hline Variables & $\begin{array}{l}\text { General } \\
(\mathrm{N}=833)\end{array}$ & $\begin{array}{c}\text { Men } \\
(n=310)\end{array}$ & $\begin{array}{l}\text { Women } \\
(n=523)\end{array}$ & $\mathrm{p}$ \\
\hline Age $^{*}$ (years of age) & $62.0(54.0-69.0)$ & $63.0(55.0-69.0)$ & $62.0(53.0-69.0)$ & 0.443 \\
\hline Years of study & $4.0(3.0-7.0)$ & $4.0(3.0-8.0)$ & $4.0(2.0-6.0)$ & 0.062 \\
\hline Formal/informal work with incomet (\%) & $217(26.0)$ & $107(49.3)$ & $110(50.7)$ & 2.000 \\
\hline Marital status with partnert (\%) & $488(58.6)$ & $216(44.3)$ & $272(55.7)$ & $<0.001$ \\
\hline Ethnicity/white colort (\%) & $261(31.3)$ & $106(40.6)$ & $155(59.4)$ & 0.248 \\
\hline Smokerst (\%) & $91(11.0)$ & $40(44.0)$ & $51(56.0)$ & \multirow{2}{*}{$<0.001$} \\
\hline Ex-smokerst (\%) & $227(27.2)$ & $136(59.9)$ & $91(40.1)$ & \\
\hline Alcohol userst (\%) & $209(25.0)$ & $132(63.2)$ & $77(36.8)$ & $<0.001$ \\
\hline Hypertensiont (\%) & $769(92.3)$ & $282(36.7)$ & $487(63.3)$ & 0.260 \\
\hline Diabetest (\%) & $413(49.5)$ & $163(39.5)$ & $250(60.5)$ & 0.182 \\
\hline Obesity† (\%) & $234(28.0)$ & $53(22.6)$ & $181(77.4)$ & $<0.001$ \\
\hline Multiple risk factors $\dagger \neq(\%)$ & $114(13.7)$ & $27(23.7)$ & $87(76.3)$ & 0.001 \\
\hline Weight ${ }^{*}(\mathrm{Kg})$ & $71,5(63.0-82.0)$ & $75.0(65.7-85.5)$ & $70.0(62.0-81.0)$ & $<0.001$ \\
\hline Stature $^{*}(\mathrm{~cm})$ & $158(152-166)$ & 167(161-171) & 155(150-159) & $<0.001$ \\
\hline Body mass index $\left(\mathrm{Kg} / \mathrm{m}^{2}\right)$ & $28.30(25.22-32.05)$ & 27.18(24.31-30.08) & $29.21(25.87-33.27)$ & $<0.001$ \\
\hline Waist perimeter§ $(\mathrm{cm})$ & $93.74 \pm 11.31$ & $94.28 \pm 10.58$ & $93.42 \pm 11.72$ & 0.284 \\
\hline Hip perimeter $(\mathrm{cm})$ & $102.0(96.0-109.0)$ & $100.0(95.0-106.0)$ & 103.0(97.0-111.0) & $<0.001$ \\
\hline Waist/height ratio* & $0.59(0.54-0.63)$ & $0.56(0.53-0.60)$ & $0.60(0.55-0.66)$ & $<0.001$ \\
\hline Waist/hip ratio* & $0.91(0.85-0.96)$ & $0.94(0.89-0.98)$ & $0.88(0.83-0.94)$ & $<0.001$ \\
\hline Systolic blood pressure* (mmhg) & $130.0(120.0-140.0)$ & $130.0(120.0-141.0)$ & $130.0(120.0-140.0)$ & 0.585 \\
\hline Diastolic blood pressure* (mmhg) & $80.0(80.0-90.0)$ & $80.0(80.0-90.0)$ & $80.0(76.0-90.0)$ & 0.044 \\
\hline Total cholesterol§ (mg/dl) & $191.4 \pm 40.7$ & $188.3 \pm 41.1$ & $193.3 \pm 40.3$ & 0.082 \\
\hline Triglycerides* (mg/dl) & $126.0(95.0-174.0)$ & $118.5(86.0-170.0)$ & $129.0(100.0-175.0)$ & 0.019 \\
\hline LDL-c ${ }^{*}(\mathrm{mg} / \mathrm{dl})$ & $111.53 \pm 34.69$ & $110.89 \pm 33.75$ & $111.91 \pm 35.26$ & 0.681 \\
\hline $\mathrm{HDL}_{-c^{*}}(\mathrm{mg} / \mathrm{dl})$ & $49.0(41.0-59.0)$ & $45.5(39.0-55.0)$ & $51.0(43.0-61.0)$ & $<0.001$ \\
\hline Ratio TG/HDL-c ${ }^{*}$ & $2.57(1.73-3.95)$ & $2.58(1.73-4.17)$ & $2.50(1.73-3.85)$ & 0.546 \\
\hline Glucose $^{*}(\mathrm{mg} / \mathrm{dl})$ & $98.0(88.0-126.0)$ & $101.0(88.0-129.0)$ & $97.0(87.0-125.0)$ & 0.188 \\
\hline Glycosylated hemoglobin* (\%) & $6.0(5.6-7.0)$ & $6.0(5.6-7.1)$ & $6.0(5.6-6.9)$ & 0.915 \\
\hline Use of medicines* (number) & $2.0(1.0-4.0)$ & $2.0(1.0-4.0)$ & $3.0(1.0-4.0)$ & 0.001 \\
\hline Use of hypoglycemic agentst (\%) & $269(32.30)$ & $102(37.9)$ & $167(62.1)$ & 0.772 \\
\hline Use of lipid-lowering† (\%) & $236(28.33)$ & $76(32.2)$ & $160(67.8)$ & 0.060 \\
\hline Creatinine $^{*}(\mathrm{mg} / \mathrm{dl})$ & $0.85(0.71-0.99)$ & $0.98(0.86-1.13)$ & $0.77(0.68-0.88)$ & $<0.001$ \\
\hline Albumin* (mg/dl) & $4.47(4.30-4.64)$ & $4.56(4.39-4.74)$ & $4.42(4.26-4.59)$ & $<0.001$ \\
\hline Phosphorus* (mg/dl) & $3.40(3.00-3.80)$ & $3.20(2.90-3.60)$ & $3.50(3.20-3.90)$ & $<0.001$ \\
\hline Calcium* (mg/dl) & $9.50(9.20-9.70)$ & $9.50(9.30-9.80)$ & $9.50(9.20-9.70)$ & 0.258 \\
\hline Glomerular filtration rate $^{*}\left(\mathrm{ml} / \mathrm{min} / 1,73 \mathrm{~m}^{2}\right)$ & $83.0(71.0-97.0)$ & $82.0(69.0-96.0)$ & $84.5(72.0-100.0)$ & 0.080 \\
\hline Microalbuminuria* (mg/dl) & $5.0(3.0-11.0)$ & $5.0(3.0-11.0)$ & $5.0(3.0-11.0)$ & 0.636 \\
\hline
\end{tabular}



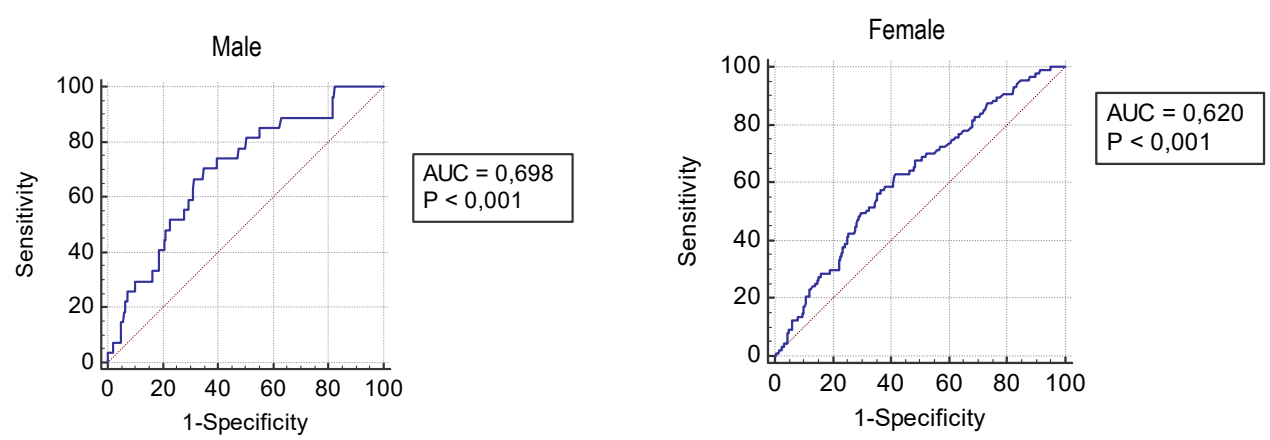

\section{$\mathrm{AUC}=$ area under the ROC curve}

Figure 1 - Receptor operation characteristic (ROC) curves for TG/HDL-c ratio and multiple risk factors for males and females.

Table 2 - Sensitivity and specificity for relationships of multiple risk factors with the TG/HDL-c ratio defined by conventional and new cutoff values for both genders

\begin{tabular}{lccc}
\hline & $\begin{array}{c}\text { Conventional cut-off value } \\
\text { Male and Female = 3.5 }\end{array}$ & $\begin{array}{c}\text { Conventional cutoff values }{ }^{5}: \\
\text { Male =3.0 and Female = 3.75 }\end{array}$ & $\begin{array}{c}\text { Suggested cutoff values: } \\
\text { Male = 3.26 and Female = 2.72 }\end{array}$ \\
\hline Female & $42.53 \%$ & $56.32 \%$ & $63.22 \%$ \\
Sensitivity & $72.48 \%$ & $64.45 \%$ & $58.26 \%$ \\
Specificity & 0.575 & 0.604 & 0.620 \\
Accuracy & & & $70.37 \%$ \\
Male & $66.67 \%$ & $51.85 \%$ & $65.02 \%$ \\
Sensitivity & $68.55 \%$ & $72.08 \%$ & 0.698 \\
Specificity & 0.676 & 0.620 & \\
Accuracy & & & \\
\hline
\end{tabular}

with an altered TG/HDL-c ratio were diabetic, used hypoglycemic agents and were active smokers, while a higher proportion of former smokers and nonsmokers showed an adequate TG/HDL-c (Table 3).

The reasons for chance $(95 \% \mathrm{CI})$ for the variables that remained in the final multivariate model were presented by gender (Table 4). Men with multiple risks were 4.58 times more likely to have an altered TG/HDL-c ratio than those without multiple risks, and frequent users of alcoholic beverages were 3.29 times more likely to have an altered TG/HDL-c ratio than non-users. Participants with a previous history of stroke had a 2.90 times higher chance of altered TG/HDL-c ratio than those without this history. A correlation was found between the altered TG/HDL-c ratio and increased TC, FG, and microalbuminuria. White individuals showed a chance of having an altered TG/HDL-c ratio that was 2.40 -fold higher than individuals of black ethnicity/color. For women with multiple risks, the chance of altered TG/ HDL-c increased by $90 \%$. Smoking cessation (former smokers) represented a protective factor, decreasing the chance of altered TG/HDL-c by 2.86-fold when compared to active smokers. The chance of altered TG/HDL-c increased by $33 \%$ for each $1 \%$ increase in $\mathrm{HbA} 1 \mathrm{c}$, by $1 \%$ in each $1 \mathrm{mg} / \mathrm{dL}$ increase of $\mathrm{FG}$, and by $61 \%$ in each $1 \mathrm{mg} /$ $\mathrm{dL}$ increase of phosphorus. Self-declared brown/yellow/ indigenous and white women were twice as likely to have altered TG/HDL-c than black women (Table 4). 
Table 3 - Sociodemographic characteristics; lifestyle; and clinical, biochemical, and anthropometric parameters according to the TG/HDL-c ratio by gender

\begin{tabular}{|c|c|c|c|c|c|c|}
\hline \multirow{2}{*}{$\begin{array}{l}\text { Variables } \\
(\mathrm{N}=833)\end{array}$} & \multicolumn{2}{|c|}{ Ratio TG/HDL-c male } & \multirow[b]{2}{*}{$\mathrm{p}$} & \multicolumn{2}{|c|}{ Ratio TG/HDL-c female } & \multirow[b]{2}{*}{$\mathrm{p}$} \\
\hline & $\begin{array}{c}\text { Adequate } \\
<3.26\end{array}$ & $\begin{array}{c}\text { Changed } \\
\geq 3.26\end{array}$ & & $\begin{array}{c}\text { Adequate } \\
<2.72\end{array}$ & $\begin{array}{c}\text { Changed } \\
\geq 2.72\end{array}$ & \\
\hline Gender (\%) & 191(61.6) & $119(38.4)$ & & $285(54.5)$ & $238(45.5)$ & \\
\hline Age $^{*}$ (years of age) & $63.0(54.0-71.0)$ & $63.0(55.0-69.0)$ & 0.556 & $61.0(53, .0-69.0)$ & $62.5(54.0-69.0)$ & 0.347 \\
\hline Years of study* & $4.0(2.0-7.0)$ & $4.0(3.0-8.0)$ & 0.194 & $4.0(2.0-6.0)$ & $4.0(3.0-6.0)$ & 0.446 \\
\hline Marital Statust (\%) & & & 0.662 & & & 0.164 \\
\hline Single & $22(71.0)$ & $9(29.0)$ & & $35(64.8)$ & $19(35.2)$ & \\
\hline Married/friendly & 132(61.1) & $84(38.9)$ & & $147(54.0)$ & $125(46.0)$ & \\
\hline Separated/divorced & $18(66.7)$ & $9(33.3)$ & & $22(44.0)$ & $28(56.0)$ & \\
\hline Widowers & $9(56.2)$ & $7(43.8)$ & & $68(58.1)$ & $49(41.9)$ & \\
\hline Ethnicity/colort (\%) & & & 0.064 & & & 0.003 \\
\hline Black & $43(74.1)$ & $15(25.9)$ & & $81(68.6)$ & $37(31.4)$ & \\
\hline Brown/yellow/indigenous & $77(63.1)$ & $45(36.9)$ & & $108(50.2)$ & $107(49.8)$ & \\
\hline White & $59(55.7)$ & $47(44.3)$ & & $80(51.6)$ & $75(48.4)$ & \\
\hline $\begin{array}{l}\text { Employment } \\
\text { situationt (\%) }\end{array}$ & & & 0.952 & & & 0.740 \\
\hline Workers with income & $64(59.8)$ & $43(40.2)$ & & $61(55.5)$ & $49(44.5)$ & \\
\hline Housewife & $3(60.0)$ & $2(40.0)$ & & $78(54.2)$ & $66(45.8)$ & \\
\hline Retired & $106(63.1)$ & $62(36.9)$ & & $129(55.6)$ & $103(44.4)$ & \\
\hline Unemployed & $18(60.0)$ & $12(40.0)$ & & $17(45.9)$ & $20(54.1)$ & \\
\hline Smokingt (\%) & & & 0.945 & & & 0.024 \\
\hline Smokers & $24(60.0)$ & $16(40.0)$ & & $22(43.1)$ & $29(56.9)$ & \\
\hline Former smokers & $85(62.5)$ & $51(37.5)$ & & $60(65.9)$ & $31(34.1)$ & \\
\hline Never smoked & $68(63.0)$ & $40(37.0)$ & & $184(54.0)$ & $157(46.0)$ & \\
\hline Alcohol userst (\%) & $76(57.6)$ & $56(42.4)$ & 0.122 & $47(61.0)$ & $30(39.0)$ & 0.235 \\
\hline Hypertensivet (\%) & 174(61.7) & 108(38.3) & 0.918 & $263(54.0)$ & $224(46.0)$ & 0.409 \\
\hline Diabeticst (\%) & $97(59.5)$ & $66(40.5)$ & 0.423 & $122(48.8)$ & $128(51.2)$ & 0.012 \\
\hline Obeset (\%) & $24(45.3)$ & $29(54.7)$ & 0.007 & $83(45.9)$ & $98(54.1)$ & 0.004 \\
\hline $\begin{array}{l}\text { Multiple risk factorst, } \\
\ddagger(\%)\end{array}$ & $8(29.6)$ & $19(70.4)$ & $<0.001$ & $32(36.8)$ & $55(63.2)$ & $<0.001$ \\
\hline $\begin{array}{l}\text { Use of medicines } \\
\text { (number of) }\end{array}$ & $2.0(1.0-4.0)$ & $2.0(1.0-3.0)$ & 0.793 & $3.0(1.0-4.0)$ & $3.0(2.0-5.0)$ & 0.080 \\
\hline $\begin{array}{l}\text { Use of hypoglycemic } \\
\text { agentst }(\%)\end{array}$ & 72(70.6) & $30(29.4)$ & 0.023 & $79(47.3)$ & $88(52.7)$ & 0.024 \\
\hline Use of lipid-lowering† (\%) & $46(60.5)$ & $30(39.5)$ & 0.823 & $83(51.9)$ & $77(48.1)$ & 0.425 \\
\hline Weight* ${ }^{*}(\mathrm{Kg})$ & $72.0(63.5-82.0)$ & $79.5(70.0-89.0)$ & $<0.001$ & 67.0(59.1-78.5) & $72.0(63.0-82.0)$ & $<0.001$ \\
\hline Stature $(\mathrm{cm})$ & $167(160-171)$ & $168(163-172)$ & 0.092 & 154(149-158) & $155(150-160)$ & 0.056 \\
\hline
\end{tabular}




\begin{tabular}{|c|c|c|c|c|c|c|}
\hline \multicolumn{7}{|l|}{ Continuation } \\
\hline Body mass index $\left(\mathrm{Kg} / \mathrm{m}^{2}\right)$ & $26.49(23.45-29.27)$ & 28.17(25.34-31.18) & $<0.001$ & $28.39(25.29-32.32)$ & $30.64(26.91-33.73)$ & 0.001 \\
\hline Waist perimeter $(\mathrm{cm})$ & $92.19 \pm 10.34$ & $97.63 \pm 10.13$ & $<0.001$ & $90.95 \pm 10.97$ & $96.31 \pm 11.93$ & $<0.001$ \\
\hline Hip perimeter* $(\mathrm{cm})$ & $99.5(93.0-104.5)$ & $101.5(96.0-106.0)$ & 0.040 & $102.0(96.0-110.5)$ & $104.0(97.5-112.0)$ & 0.035 \\
\hline Waist/height ratio* & $0.56(0.52-0.59)$ & $0.59(0.55-0.62)$ & $<0.001$ & $0.59(0.54-0.64)$ & $0.62(0.56-0.67)$ & $<0.001$ \\
\hline Waist/hip ratio* & $0.92(0.88-0.96)$ & $0.96(0.92-1.00)$ & $<0.001$ & $0.87(0.82-0.93)$ & $0.90(0.85-0.96)$ & $<0.001$ \\
\hline $\begin{array}{l}\text { Systolic blood pressure* } \\
(\mathrm{mmHg})\end{array}$ & $130.0(120.0-140.0)$ & $\begin{array}{c}130.0(120, .0- \\
145.0)\end{array}$ & 0.691 & 130.0(120.0-140.0) & $130.0(120.0-140.0)$ & 0.484 \\
\hline $\begin{array}{l}\text { Diastolic blood pressure* } \\
(\mathrm{mmHg})\end{array}$ & $80.0(80.0-90.0)$ & $80.0(80.0-90.0)$ & 0.903 & $80.0(77.0-88.0)$ & $80.0(74.0-90.0)$ & 0.608 \\
\hline Total cholesterol§ (mg/dL) & $182.87 \pm 37.44$ & $196.92+45.24$ & 0.005 & $190.47 \pm 36.95$ & $196.76 \pm 43.84$ & 0.080 \\
\hline Triglycerides* (mg/dL) & $95.0(77.0-115.0)$ & $195.0(153.0-262.0)$ & $<0.001$ & $102.0(85.0-121.0)$ & $178.0(150.0-223.0)$ & $<0.001$ \\
\hline LDL-c* $(\mathrm{mg} / \mathrm{dL})$ & 107.0(83.8-133.0) & 112.2(86.2-138.5) & 0.647 & $105.8(88.6-131.0)$ & $107,8(88.6-136.6)$ & 0.469 \\
\hline HDL-c ${ }^{*}(\mathrm{mg} / \mathrm{dL})$ & $51.0(44.0-61.0)$ & $39.0(34.0-44.0)$ & $<0.001$ & $59.0(52.0-67.0)$ & $43.0(38.0-48.0)$ & $<0.001$ \\
\hline Glucose (mg/dL) & $96.0(87.0-126.0)$ & 108.0(94.0-135.0) & 0.001 & $95.0(86.0-119.0)$ & $101.0(89.0-134.0)$ & 0.005 \\
\hline $\begin{array}{l}\text { Glycosylated } \\
\text { hemoglobin* }(\%)\end{array}$ & $5.9(5.5-7.1)$ & $6.1(5.7-7.3)$ & 0.040 & $5.9(5.6-6.9)$ & $6.1(5.7-7.0)$ & 0.052 \\
\hline Creatinine $^{*}(\mathrm{mg} / \mathrm{dL})$ & $0.96(0.84-1.10)$ & $1.00(0.89-1.18)$ & 0.037 & $0.77(0.68-0.87)$ & $0.77(0.68-0.89)$ & 0.477 \\
\hline Albumin* (mg/dL) & $4.54(4.37-4.71)$ & $4.61(4.46-4.78)$ & 0.035 & $4.40(4.26-4.57)$ & $4.45(4.28-4.61)$ & 0.119 \\
\hline Phosphorus* (mg/dL) & $3.20(2.90-3.60)$ & $3.20(2.80-3.50)$ & 0.666 & $3.50(3.10-3.80)$ & $3.60(3.20-3.90)$ & 0.057 \\
\hline Calcium* (mg/dL) & $9.50(9.30-9.70)$ & $9.50(9.30-9.80)$ & 0.442 & $9.50(9.20-9.70)$ & $9.50(9.30-9.80)$ & 0.003 \\
\hline $\begin{array}{l}\text { Glomerular filtration rate } \\
\left(\mathrm{mL} / \mathrm{min} / 1,73 \mathrm{~m}^{2}\right)\end{array}$ & $84.0(72.0-97.0)$ & 79.0(67.0-92.0) & 0.085 & 85.0(73.0-101.0) & 83.0(71.0-99.0) & 0.319 \\
\hline $\begin{array}{l}\text { Microalbuminuria* } \\
(\mathrm{mg} / \mathrm{dL})\end{array}$ & $5.0(3.0-10.0)$ & $6.0(3.0-15.0)$ & 0.076 & $5.0(3.0-10.0)$ & $6.0(4.0-13.0)$ & 0.061 \\
\hline
\end{tabular}

\section{Discussion}

In the present study, the cutoff points for the TG/ HDL-c ratio of 3.26 for men and 2.72 for women, adults, and the elderly, hypertensive and/or diabetic, users of PHC were identified. These results are lower than those used in Brazil in both male and female elderly individuals, ${ }^{8}$ those found for Japanese adults, ${ }^{5}$ and much lower than conventional cutoff values of 3.75 in men and of 3.00 in women calculated using each of the cutoff values for triglycerides $(150 \mathrm{mg} / \mathrm{dL}$ in men and women) and HDL cholesterol $(40 \mathrm{mg} / \mathrm{dL}$ in men and $50 \mathrm{mg} / \mathrm{dL}$ in women).

High plasma level of LDL-c and TG, and low levels of HDL-c, are important factors of CVR. ${ }^{3,21}$ Lipid reasons can be used for early detection of individual CVR. ${ }^{5}$
The LDL-c/HDL-c ratio is a classic index for predicting $\mathrm{AD}$, but the TG/HDL-c ratio is the best predictor for acute myocardial infarction, associated with insulin resistance and metabolic syndrome. ${ }^{5}$ The TG/HDL-c ratio correlates directly with plasma LDL-c levels, type $\mathrm{B},{ }^{5,8}$ reported as an independent CVR factor. ${ }^{5}$ To identify cardiac and metabolic threats, it is important to use different TG/ HDL-c ratio cutoff points between genders, ${ }^{5,11}$ as the HDL-c level is higher in women. ${ }^{5}$ Different cutoff values for men and women are, in fact, used in the National Cholesterol Education Program's (NCEP) criteria for metabolic syndrome. ${ }^{22}$ Therefore, it is reasonable that there is also a gender difference in the cutoff of the TG/ HDL-c ratio: the values were higher in men than in women (Figure 1). Thus, it is preferable to use different cutoff values of the TG/HDL-c ratio for men and women. 


\begin{tabular}{|c|c|c|}
\hline \multirow{2}{*}{ Analyzed variable } & Male & Female \\
\hline & OR $(95 \% \mathrm{CI})$ & OR $(95 \% \mathrm{CI})$ \\
\hline Multiple Risks (Yes) & $4.58(1.78-11.76)$ & $1.90(1.13-3.20)$ \\
\hline Glucose (mg/dL) & $1.006(1.000-1.011)$ & $1.013(1.005-1.021)$ \\
\hline Ethnicity (Black) & 1 & 1 \\
\hline Ethnicity (Brown/Yellow/Indigenous) & $1.61(0.75-3.46)$ & $2.15(1.31-3.54)$ \\
\hline Ethnicity (White) & $2.40(1.10-5.22)$ & $2.04(1.20-3.47)$ \\
\hline Alcohol Use (Yes) & $3.29(1.13-9.58)$ & NA \\
\hline Stroke (Yes) & $2.90(1.06-7.92)$ & NA \\
\hline Total Cholesterol (mg/dL) & $1.01(1.00-1.02)$ & NA \\
\hline Microalbuminuria (mg/dL) & $1.002(1.000-1.005)$ & NA \\
\hline Smoking (Smoker) & NA & 1 \\
\hline Smoking (Former Smoker) & NA & $0.35(0.16-0.74)$ \\
\hline Smoking (Never Smoked) & NA & $0.54(0.28-1.02)$ \\
\hline Glycosylated Hemoglobin (\%) & NA & $1.33(1.04-1.70)$ \\
\hline Serum Phosphorus (mg/dL) & NA & $1.61(1.10-2.35)$ \\
\hline
\end{tabular}

NA $=$ Not applicable

It was evidenced that the altered TG/HDL-c ratio, identified from the cutoff points found in this study, was associated with the presence of multiple risks (AH, DM, and obesity), ethnicity, alcohol use, smoking, history of stroke; $\mathrm{CT}$, FG and $\mathrm{HbA1c}$ dosages; and high microalbuminuria and high serum phosphorus. Other studies have identified associations between the TG/HDL-c ratio and several cardiometabolic risk factors, such as alcohol use, $^{7}$ smoking, ${ }^{8}$ metabolic syndrome, ${ }^{23,24}$ oxidative ${ }^{25}$ and inflammatory profiles, ${ }^{12,25}$ adverse events, ${ }^{10,26}$ various anthropometric parameters, ${ }^{5,8,9,24,27}$ dyslipidemias, ${ }^{12,24,27}$ HA. ${ }^{5,8,11}$ DM,${ }^{5,8,11,24,28}$ insulin resistance, ${ }^{11,23,28,29}$ and renal function. ${ }^{30}$ In this sense, the cutoff points found represent the CVR well and are therefore good risk markers for the studied population.

The cutoff values of the TG/HDL-c ratio can be obtained through quartiles; ${ }^{10}$ tertiles; ${ }^{11}$ for convenience, from values already used by other researchers; $; 8,9,26,28,30$ or even calculated through the ROC curve. ${ }^{5}$ Gaziano et al. $(1997)^{10}$ calculated the relative risks per quartiles, comparing the TG/HDL-c ratio levels of the second, third, and fourth quartiles with those of the first quartile. Ain et al. $(2019)^{11}$ divided the TG/HDL-c ratio into three tercis (0.1-3.59; 3.60-7.18; and 7.19-10.3). Some authors agreed on different TG/HDL-c ratio cutoff values for the sexes (2.5 for women and 3.5 for men, ${ }^{9}$ or 3.00 for women and 3.75 for men $^{5}$ ), while others pre-established the values regardless of gender $\left(2.5^{26} ; 3.0^{28,29} ; 3.5^{8}\right.$ and $\left.3.8^{30}\right)$, or they calculated them by ROC analysis (2.967 for men and 2.237 for women $)^{5}$.

The importance of identifying cutoff values by ROC analysis is due to obtaining more satisfactory values for this population (hypertensive and diabetic), which presents more CVR factors, in the instance where it is attended (PHC). The cutoff for the TG/ HDL-c ratio depends on its associated result, and a result that produces greater accuracy in ROC analysis is preferable to determine the cutoff value of the TG/ HDL-c ratio. However, because they are obtained for a specific population, the suggested cutoff cannot be extrapolated to the population in general. However, in a study of cardiometabolic risk factors $(\mathrm{AH}, \mathrm{DM}$, and visceral obesity) in periodic health examination records of 10,196 Japanese adults, it was concluded that the 
power of discrimination of cardiometabolic risk factors of the TG/HDL-c ratio, using conventional cutoff values and obtained by ROC analysis, were similar when applying both methods. ${ }^{5}$ The values suggested in the studies mentioned above or presented in the study by Wakabayashi and Daimon (2019) ${ }^{5}$ may not fit this population, as they were conducted in other countries and/or with populations with CVRs that were different from those to which hypertensive and/or diabetic patients are subject, or because they were not calculated, but obtained for convenience in the literature. In the present study, the accuracy values for the TG/HDL-c ratio in relation to multiple risks ( $\mathrm{AH}, \mathrm{DM}$, and obesity) were 0.698 in men and 0.620 in women (Figure 1), which are generally evaluated as low precision (AUC: $0.5 \sim 0.7$ ) but were higher than the accuracy presented by conventional cutoff values (Figure 1). Recent prospective studies conducted in Iran ${ }^{31}$ and China ${ }^{32}$ showed similar accuracy (0.575 and 0.647).

Considering that the components (TG and HDL-c) are simple, and are already found in routine laboratory tests, ${ }^{23}$ the TG/HDL-c ratio can be easily obtained from the patient's lipid profile., ${ }^{5,-9}$ The use of CVR predictors is relevant in clinical practice, ${ }^{9}$ and the use of the TG/HDL-c ratio as one of these indices can avoid the indiscriminate use of laboratory tests and related expenses. ${ }^{23}$ In addition, the TG/HDL-c ratio has specific characteristics, such as simplicity, low cost, applicability, ${ }^{27}$ ease of execution, ${ }^{5}$ reliability, practicality, speed in obtaining results, and non-invasive test qualities, ${ }^{8}$ making it a useful indicator to predict CVR in routine and screening tests, ${ }^{5}$ especially in the context of primary health care. ${ }^{8}$

\section{Strengths and limitations of the study}

The present study presents as strengths the achievement of the cutoff values of the TG/HDL-c ratio by ROC analysis with a more satisfactory and effective result to discriminate CVR; having been conducted with adults and the elderly - a population with a tendency to present more CVR-factors, and at the level of PHC - aninstance in which hypertensive and diabetic patients are treated. Limitations of the study include a cross-sectional design, which is insufficient to express a causal association between the TG/HDL-c ratio and the studied variables; the difficulty of comparison with other studies due to the methodological differences of obtaining results and the cutoff values of TG/HDL-c; as well as the non-analysis of food intake and physical activity data. It is suggested that longitudinal, multicenter, and/or prospective additional studies should be conducted to discuss the causative relationships and temporal correlations of CVRs with the TG/HDL-c ratio.

\section{Conclusion}

For a population of hypertensive and/or diabetic patients, cutoff values for the TG/HDL-c ratio (3.26 for males and 2.72 for females) were lower than those commonly used in clinical practice. These values showed greater accuracy and sensitivity and less specificity than conventional values. It was also observed that the new cutoff points indicative of altered TG/HDL-c were associated with the presence of multiple risks (AH, DM, and Obesity), ethnicity, alcohol use, smoking, history of stroke, and increased values of TC, FG, HbA1c, microalbuminuria, and serum phosphorus.

These results suggest the use of new cutoff points in the clinical practice of follow-up of patients with $\mathrm{AH}$ and DM in PHC, aiming to achieve early screening and the appropriate treatment of risk factors that may indicate an undesirable prognosis in this population.

\section{Acknowledgment}

The authors express gratitude to the researchers of the Laboratory of Studies in Health Planning and Management (LabPlanGest) and the Innovation Program in University Teaching (PRODUS) of the Federal University of Viçosa who participated in the collection and tabulation of data.

\section{Author contributions}

Conception and design of the research: Silva EF, Moreira TR. Analysis and interpretation of the data: Silva EF, Moreira TR. Statistical analysis: Moreira TR. Obtaining financing: Cotta RMM. Writing of the manuscript: Silva EF. Critical revision of the manuscript for intellectual content: Mendonça ET, Oliveira DM, Cardoso SA, Colodette RM, Cotta RMM, Moreira TR. Supervision / as the major investigador: Cotta RMM. 


\section{Potential Conflict of Interest}

No potential conflict of interest relevant to this article was reported.

\section{Sources of Funding}

This study was supported by the Research Support Foundation of the State of Minas Gerais (FAPEMIG) for the project "Prevention of diseases and diseases in patients with hypertension in the context of primary health care: chronic kidney disease on the agenda". Case CSA-APQ-03510-13. Notice 14/2013.

\section{References}

1. Soares LP, Fabbro ALD, Silva AS, Sartorelli DS, Franco LF, Kuhn PC, et al. Cardiovascular Risk in Xavante Indigenous Population. Arq Bras Cardiol. 2018;110(6):542-50. doi: 10.5935/abc.20180090.

2. Silva ARA, Dourado KF, Pereira PB, Lima DSC, Fernandes AO, Andrade AM, et al. Razão TG/HDL-c e Indicadores Antropométricos Preditores de Risco para Doença Cardiovascular. Rev Bras Cardiol. 2012;25(1):41-9.

3. Garcez MR, Pereira JL, Fontanelli MM, Marchioni DM, Fisberg RM. Prevalence of Dyslipidemia According to the Nutritional Status in a Representative Sample of São Paulo. Arq Bras Cardiol. 2014;103(6):47684. doi: 10.5935/abc. 20140156

4. Sicchieri LB. Caracterização da Lipoproteína de Baixa Densidade (LDL) por Meios Espectroscópicos [dissertation]. São Paulo: Universidade de São Paulo; 2012

5. Wakabayashi I, Daimon T. Comparison of Discrimination for CardioMetabolic Risk by Different Cut-Off Values of the Ratio of Triglycerides to HDL Cholesterol. Lipids Health Dis. 2019;18(1):156. doi: 10.1186/ s12944-019-1098-0.

6. Précoma DB, Oliveira GMM, Simão AF, Dutra OP, Coelho OR, Izar MCO, et al. Atualização da Diretriz de Prevenção Cardiovascular da Sociedade Brasileira de Cardiologia - 2019. Arq Bras Cardiol. 2019; 113(4):787-891. doi: 10.5935/abc.20190204

7. Andrade MIS, Dourado KF, Lima CR, Orange LG, Bento RA, Rodrigues DAS, et al. Razão Triglicerídeo/HDL-C como Indicador de Risco Cardiovascular em Alcoolistas Crônicos. Rev Bras Cardiol. 2012;25(4):267-75.

8. Martins MV, Souza JD De, Martinho KO, Franco FS, Tinôco ALA. Associação entre razão Triglicerídeos e HDL-colesterol e fatores de risco cardiovascular em idosos atendidos na estratégia saúde da família de Viçosa, MG. Rev Bras Geriatr e Gerontol. 2017;20(2):236-43. doi: 10.1590/1981-22562017020.160059.

9. Almeida AF, Sena MHLG, Gomes TS, Ramos LB, Gobatto ALN, Conceição MEP, et al. Razão TG/HDL-c, Indicadores Antropométricos e Bioquímicos de Risco Cardiovascular no Renal Crônico em Tratamento Conservador. Nutr Clin y Diet Hosp. 2017;37(4):10-6. doi: 10.12873/374fortes.

10. Gaziano JM, Hennekens CH, O'Donnell CJ, Breslow JL, Buring JE. Fasting Triglycerides, High-Density Lipoprotein, and Risk of Myocardia Infarction. Circulation. 1997;96(8):2520-5. doi: 10.1161/01.cir.96.8.2520.

11. Ain QU, Asif N, Alam A, Gilani M, Shahzad N, Sheikh W. Triglyceridesto-HDLC Ratio as a Marker of Cardiac Disease and Vascular Risk Factors in Adults. J Coll Physicians Surg Pak. 2019;29(11):1034-7. doi: 10.29271/ jcpsp.2019.11.1034.

12. Vieira EA, Carvalho WA, Aras Júnior R, Couto FD, Couto RD. Razão Triglicérides/HDL-C e proteína C Reativa de Alta Sensibilidade

\section{Study Association}

This article is part of the Master's thesis by Eunice Ferreira da Silva, from the Graduate Program in Health Sciences of the Federal University of Viçosa.

\section{Ethics approval and consent to participate}

This study was approved by the Ethics Committee of the Federal University of Viçosa under the protocol number 1.203.173 - CAAE: 47356115.3.0000.5153. All the procedures in this study were in accordance with the 1975 Helsinki Declaration, updated in 2013. Informed consent was obtained from all participants included in the study.

na Avaliação do Risco Cardiovascular. J. Bras. Patol. Med. Lab. 2011;47(2):113-8. doi: 10.1590/S1676-24442011000200004.

13. Comini LO, Oliveira LC, Borges LD, Dias HH, Batistelli CRS, Silva LS, et al. Individual and Combined Components of Metabolic Syndrome with Chronic Kidney Disease in Individuals with Hypertension and/ or Diabetes Mellitus Accompanied by Primary Health Care. Diabetes Metab Syndr Obes. 2020;13:71-80. doi: 10.2147/DMSO.S223929.

14. Malachias MVB, Souza WKSB, Plavnik FL, Rodrigues CIS, Brandão AA, Neves MFT, et al. 7 Diretriz Brasileira de Hipertensão Arterial. Arq Bras Cardiol. 2016;107(3Supl.3):1-83. doi: 10.5935/abc.20160152.

15. Jelliffe DB. World Health Organization. The assessment of the nutritional status of the community [Internet]. Geneva: World Health Organization; 1966 (cited 2021 Jul 07). Available from: https://apps.who.int/iris/ handle/10665/41780

16. World Health Organization. Obesity: Preventing and Managing the Global Epidemic. Geneva: WHO Tech Rep Ser; 2000.

17. Lipschitz DA. Screening for Nutritional Status in the Elderly. Prim Care. 1994;21(1):55-67.

18. Ashwell M, Hsieh SD. Six Reasons Why the Waist-to-Height Ratio is a Rapid and Effective Global Indicator for Health Risks of Obesity and How its Use could Simplify the International Public Health Message on Obesity. Int J Food Sci Nutr. 2005;56(5):303-7. doi: 10.1080/09637480500195066.

19. Oliveira JEP, Montenegro RM Jr, Vencio S, Foss-Freitas MC. Diretrizes da Sociedade Brasileira de Diabetes 2017-2018. São Paulo: Clannad; 2018.

20. Kirsztajn GM, Filho NS, Draibe SA, Netto MV, Thomé FS, Souza E, Bastos MG. Fast reading of the KDIGO 2012: guidelines for evaluation and management of chronic kidney disease in clinical practice. J Bras Nefrol. 2014;36(1):63-73. doi: 10.5935/0101-2800.20140012.

21. Silva RC, Diniz MF, Alvim S, Vidigal PG, Fedeli LM, Barreto SM. Physical Activity and Lipid Profile in the ELSA- Brasil Study. Arq Bras Cardiol. 2016;107(1):10-9. doi: 10.5935/abc.20160091.

22. Nakazone MA, Pinheiro A, Braile MC, Pinhel MA, Sousa GF, Pinheiro S $\mathrm{Jr}$, et al. Prevalence of metabolic syndrome using NCEP-ATPIII and IDF definitions in Brazilian individuals. Rev Assoc Med Bras. 2007;53(5):40713. doi: 10.1590/s0104-42302007000500016.

23. Baez-Duarte BG, Zamora-Gínez I, González-Duarte R, Torres-Rasgado E, Ruiz-Vivanco G, Pérez-Fuentes R, Celis TMRGOD. Triglyceride/ High-Density Lipoprotein Cholesterol (TG/HDL-C) Index as a Reference Criterion of Risk for Metabolic Syndrome (MetS) and Low Insulin Sensitivity in Apparently Healthy Subjects. Gac Med Mex. 2017;153(2):152-8 
24. Girona J, Amigó N, Ibarretxe D, Plana N, Rodríguez-Borjabad C, Heras M, et al. HDL Triglycerides: A New Marker of Metabolic and Cardiovascular Risk. Int J Mol Sci. 2019;20(13):3151. doi: 10.3390/ijms20133151.

25. Baez-Duarte BG, Ríos-Fuentes JC, Zamora-Ginez I, Mendoza-Carrera F, Briones-Rojas R. Relationship of Triglycerides/High Density LipoproteinCholesterol Index With Antioxidant Defense And Outstanding Association With High Sensitive C-Reactive Protein In Mexican Subjects. Int J Public Heal Clin Sci. 2018;5(2):169-79.

26. Sultani R, Tong DC, Peverelle M, Lee YS, Baradi A, Wilson AM. Elevated Triglycerides to High-Density Lipoprotein Cholesterol (TG/HDL-C) Ratio Predicts Long-Term Mortality in High-Risk Patients. Heart Lung Circ. 2020;29(3):414-21. doi: 10.1016/j.hlc.2019.03.019.

27. Miralles CSW, Wollinger LM, Marin D, Genro JP, Contini V, Dal Bosco SM. Waist-to-Height Ratio (WHtR) and Triglyceride to HDL-C ratio (TG/HDL-c) as Predictors of Cardiometabolic Risk. Nutr Hosp. 2015;31(5):2115-21. doi: 10.3305/nh.2015.31.5.7773.

28. Borrayo G, Basurto L, González-Escudero E, Diaz A, Vázquez A, Sánchez L, et al. TG/HDL-C Ratio as Cardio-Metabolic Biomarker Even in Normal Weight Women. Acta Endocrinol. 2018;14(2):261-7. doi: 10.4183/aeb.2018.261.
29. Pantoja-Torres B, Toro-Huamanchumo CJ, Urrunaga-Pastor D, GuarnizoPoma M, Lazaro-Alcantara H, Paico-Palacios S, et al. High Triglycerides to HDL-Cholesterol Ratio is Associated with Insulin Resistance in Normal-Weight Healthy Adults. Diabetes Metab Syndr. 2019;13(1):382-8. doi: 10.1016/j.dsx.2018.10.006.

30. Moraes LL, Santos ALG dos, Dias LPP, Oliveira D de A, Mafra D, Martins ICV da S. Identificação de Risco Cardiovascular pela Razão Triglicerídeo/HDL-Colesterol em Pacientes com Doença Renal Crônica em Hemodiálise. Sci Med. 2017;27(3):7. doi:10.15448/19806108.2017.3.27369.

31. Gharipour M, Sadeghi M, Dianatkhah M, Nezafati P, Talaie M, Oveisgharan $\mathrm{S}$, et al. Comparison between European and Iranian Cutoff Points of Triglyceride/High-Density Lipoprotein Cholesterol Concentrations in Predicting Cardiovascular Disease Outcomes. J Clin Lipidol. 2016;10(1):143-9. doi: 10.1016/j.jacl.2015.10.008.

32. Deng QW, Li S, Wang H, Lei L, Zhang HQ, Gu ZT, et al. The ShortTerm Prognostic Value of the Triglyceride-to-High-Density Lipoprotein Cholesterol Ratio in Acute Ischemic Stroke. Aging Dis. 2018;9(3):498-506. doi: 10.14336/AD.2017.0629. 